\title{
Effect of variable degrees of jejunal resection upon different clinico-biochemical parameters in dogs
}

\author{
Muhammad Sohail Dilawer', Muhammad Arif Khan², Zain ul Abidin ${ }^{1}$,*, Shahan Azeem², \\ Khalid Abdul Majeed ${ }^{2}$, Adeel Shahbaz ${ }^{2}$, Aamir Riaz Khan ${ }^{1}$ \\ ${ }^{1}$ Veterinary Research Institute, Zarrar Shaheed Road, Lahore Cantt. 13, Pakistan \\ ${ }^{2}$ Department of Clinical Medicine and Surgery, University of Veterinary and Animal Sciences, Lahore 54000, Pakistan
}

(Received: October 24, 2011; Revised: November 23; Accepted: November 24, 2011)

\begin{abstract}
Dogs are considered to be the best companions of human beings due to their loyalty, obedience and pleasant disposition. Jejunum is the largest part of small intestine mainly involved in absorption of nutrients. Jejunal resection up to $80 \%$ allows normal weight gain while resection up to $90 \%$ increased morbidity and mortality. In the present study, 20 dogs were divided into 4 groups based on the degree of jejunal resection i.e. A ( $70 \%$ resection), B ( $80 \%$ resection) and C (100\% resection) while group D served as control. Dogs in the $70 \%$ and $80 \%$ jejunal resection group showed normal growth and function while $100 \%$ jejunal resection resulted in weight loss and alteration of hematological and biochemical parameters.
\end{abstract}

Keywords : clinico-biochemical parameters, dogs, jejunal resection, weight

\section{Introduction}

Dogs are considered to be the most faithful companions for human due to their obedience, loyalty and pleasant dispositions. Dogs appeared about twenty million years ago on the earth [7].

Ailementary tract provides the nutrients, water, and electrolytes to the body, and includes small and large intestines. Each part of this tract performs its specific function. Some parts are involved in simple passage and breakdown of food (stomach) while small and large intestines are involved in digestion and absorption of food [3].

Small intestine is divided in to three parts i.e. jejunum, ileum and duodenum. Jejunum is the longest part of small intestine situated between duodenum and ileum. It is also the most mobile and free part of whole ailementary canal. In carnivores, the jejunal coils occupy the ventral part of abdomen between the stomach and bladder, lying on deep layer of greater omentum. The long mesojejunum imposes little restraint which allows the gut to move freely in response to respiratory and other movements [4].

Intestinal resection and anastomosis are performed for various lesions in small animals, such as mechanical obstructions, regional peritonitis, and abdominal abscess. Resection up to $80 \%$ of small intestine in puppies may allow for normal weight gain whereas resection of $90 \%$ produces morbidity and mortality [2].

Based on the published reports, the present study was designed to investigate the effects of resection of various lengths of jejunum i.e. $70 \%, 80 \%$ and $100 \%$ in dogs upon different clinico-biochemical parameters in dogs.

\section{Materials and Methods}

Twenty mongrel dogs of both sexes were selected with an age between six months and 3 years. Dogs were kept under comprehensive monitoring with regard to physical exam (faecal test, complete blood cell [CBC] etc.) prior to surgery which was performed at the Surgery section, Department of Clinical Medicine and Surgery, University of Veterinary and Animal Sciences, Lahore, Pakistan. Dogs were shifted to kernels at least 10 days prior to surgery to acclimatize them to frequent handling in their new environment. The dogs were randomly divided into 4 groups containing 5 dogs each. $70 \%, 80 \%$ and $100 \%$ resection of jejunum was performed in group $\mathrm{A}, \mathrm{B}$ and $\mathrm{C}$, respectively, while

*Corresponding author

Tel: +92-33-3811-6906, Fax: +92-42-9922-0142

E-mail: ranazain848@yahoo.com 
group D served as positive control in which end to end anastomosis was performed without any resection. Surgery was conducted through ventral midline laprotomy from umbilicus to a variable distance caudally under general anaesthesia.

\section{Parameters studied}

Physical examination: It was performed to check the general health conditions including weight gain or weight loss. Body weight was measured at different intervals i.e. pre-operatively, $15,30,45,60,75$ and 90 days post-operatively.

Faecal examination: Fecal consistency was examined to determine the functional status of small intestines.

Hematological parameters by hematological analyzer: Peripheral blood was collected in EDTAcontaining tubes at days $15,30,45,60,75$ and 90 days after surgery and following hematological parameters were determined by hematological analyzer (Abacus, Austria): a) Hematocrit (Hct), b) total leukocytic count, c) granulocytic count, d) erythrocytic count, e) hemoglobin $(\mathrm{Hb}), \mathrm{f})$ mean corpuscular volume (MCV), g) mean corpuscular hemoglobin $(\mathrm{MCH}), \mathrm{h})$ mean corpuscular hemoglobin concentration (MCHC), and i) platelets.

Electrolytes evaluation: Serum samples were evaluated for different electrolytes i.e. sodium $\left(\mathrm{Na}^{+}\right)$ions, potassium $\left(\mathrm{K}^{+}\right)$ions, chloride $\left(\mathrm{Cl}^{-}\right)$ions and biocarbonate $\left(\mathrm{HCO}_{3}^{-}\right)$ions by chemistry automatic analyser ROCHE912 (The Medical Laboratories, Pakistan).

\section{Post-mortem studies}

Dogs expired during the study were subjected to postmortem examination to evaluate the changes in anastmosed areas. At the termination of experiment (3 months), all survived dogs were euthanized by concentrated magnesium sulphate solution given intravenously and anastomosed sites of jejunum were examined along with abdominal cavity for any other change or lesion.

\section{Statistical analysis}

The data from the study was analyzed by one way analysis of variance (ANOVA) using SPSS (ver. 10.0; SPSS, USA) [11].

\section{Results}

\section{Body weight}

Loss of body weight was noticed at day 15 in all



Fig. 1. Line graph showing body weight of dogs of all groups at different intervals.

groups, while an increase was noticed at later time points except in group $\mathrm{C}$. The mean body weights of all the groups at different intervals are graphically shown in Fig. 1.

\section{Faecal consistency}

A feces grading was done as 1) watery, 2) moist, or 3) soft and firm. In group A, B and C initially feces were watery or moist which became soft and firm with the passage of time except in group $\mathrm{C}$ where it remained watery and moist. Feces of group D remained soft and firm throughout the experiment (Data not shown).

\section{Hematological parameters}

The white blood cells (WBCs) count of group A, B, and $\mathrm{C}$ was not different from control at day 15,60 and 75 while WBCs count in group A was significantly higher than control at day 30 and 45. And WBCs count of group $\mathrm{A}, \mathrm{B}$ and $\mathrm{C}$ was significantly higher than control at day 90 (Fig. 2).

Lymphocytic count of all the groups was not different from control at day 15, 45, 60 and 75 while group B was significantly higher than control at day 30 and 90 (Fig. 2).

Granulocytic count of all the groups was not different from control at day 15, 60 and 75. Group A had significantly high granulocytic count at day 30 and 45 . Group A and C had significantly higher granulocytic count at day 90 (Fig. 2).

Hct values of all groups were not different from control at day 15, 30 and 60 while it was significantly low in group A and C at day 45 . At day 75 , group C had significantly lower Hct value than control while it was significantly higher at day 90 (Fig. 3).

Erythrocytic count of all groups was not different 


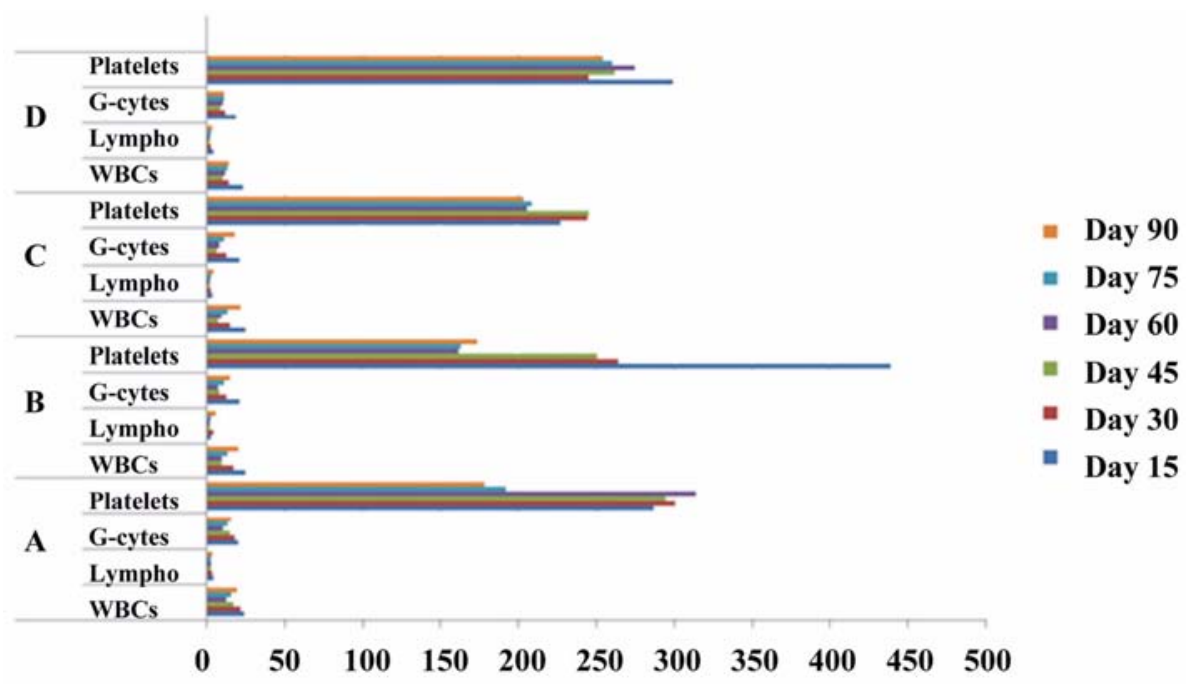

Fig. 2. Bar graph showing white blood cells (WBCs), lymphocytic, granulocytic (G-cytes), platelet counts of all groups $(\mathrm{A} \sim \mathrm{D})$ at different intervals.

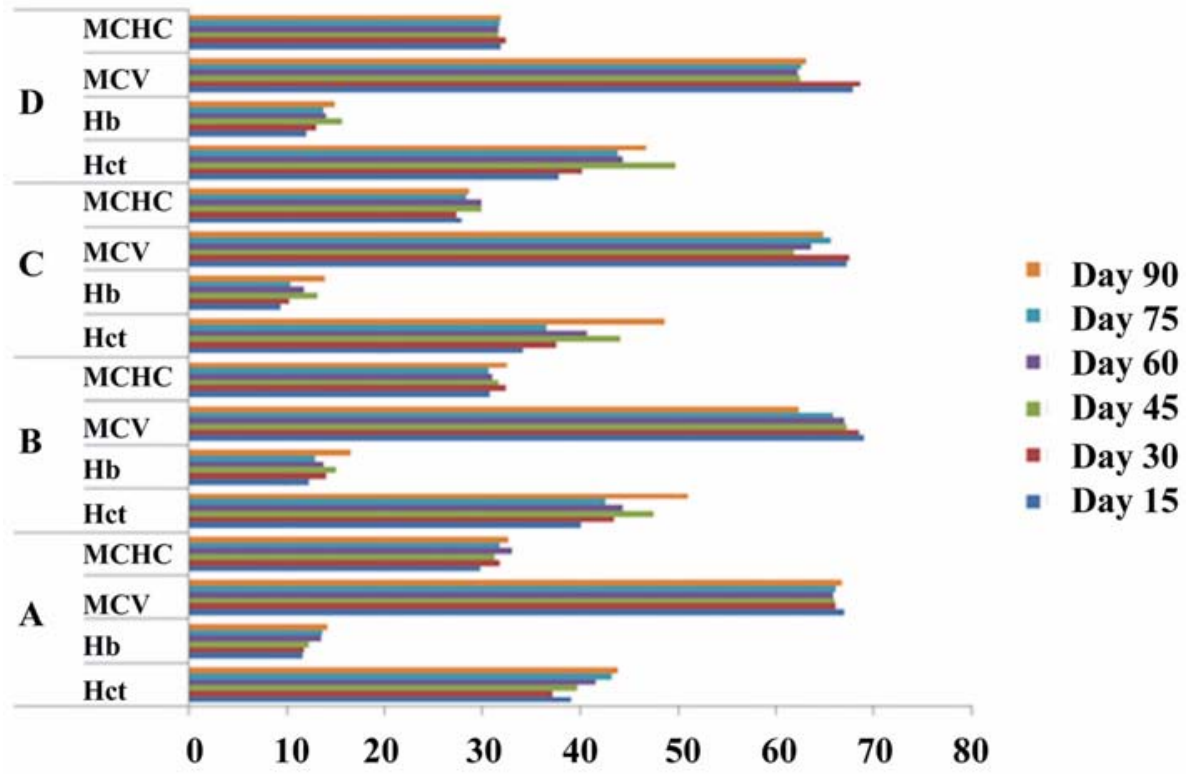

Fig. 3. Bar graph showing Hematocrit (Hct), hemoglobin $(\mathrm{Hb})$, mean corpuscular volume (MCV) and mean corpuscular hemoglobin concentration $(\mathrm{MCHC})$ of all groups $(\mathrm{A} \sim \mathrm{D})$ at different intervals.

from control at day 15, 30 and 60. It was significantly lower in all groups than control at day 45. Erythrocytic count of group $\mathrm{C}$ was significantly lower than control at day 75 while group A had significantly low at day 90 (Data not shown).

Hemoglobin concentration of group $\mathrm{C}$ was significantly lower than control at day 15, 30, 45, 60 and 75. Group A had significantly lower value at day 45. Group B had significantly higher value than control at day 90 (Fig. 3).

MCV of all the groups were not significantly different from control at day 15, 30 and 90. Group A and B had significantly higher values than control at day 45, 60 and 75 (Fig. 3). 


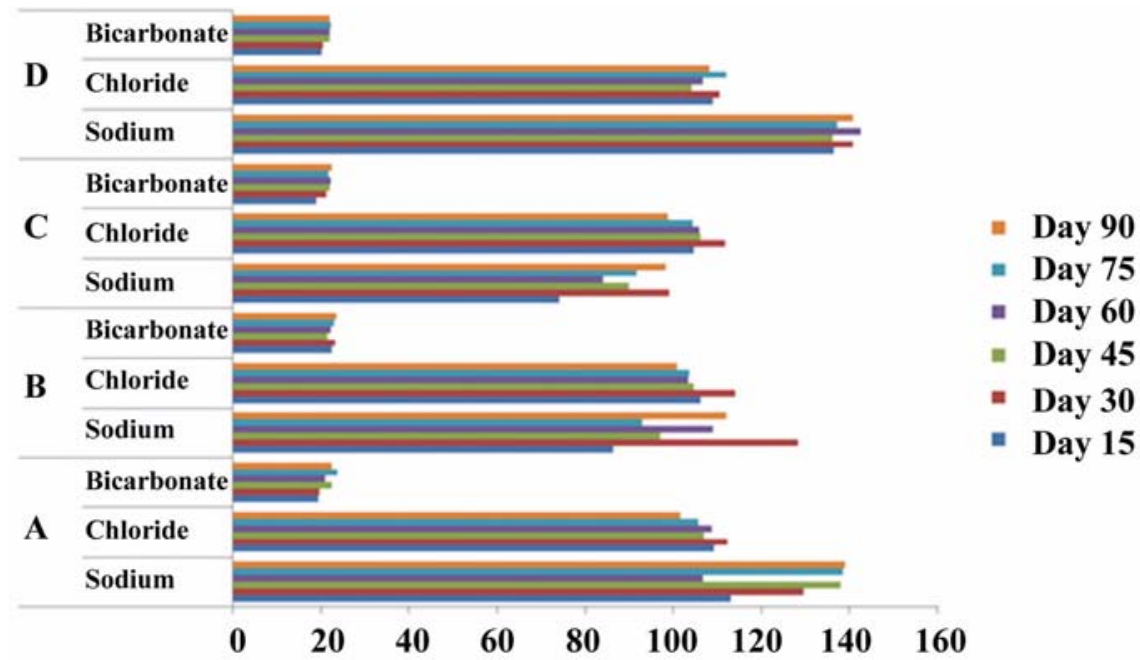

Fig. 4. Bar graph showing bicarbonate, chloride and sodium values of all groups (A D) at different intervals.

$\mathrm{MCH}$ of group $\mathrm{A}$ and $\mathrm{C}$ was significantly lower than control at day 15 . Group $\mathrm{C}$ had significantly lower value than control at day 30, 45 and 75. Group A and B had significantly higher values than control at day 60 . Group A had significantly higher value at day 90 (Data not shown).

MCHC of group A, B and C was significantly lower than control at day 15 . Group $\mathrm{C}$ had significantly lower values at day 30, 45, 60, 75 and 90 (Fig. 3).

Platelet values of all groups were not significantly different from control at day 30, 45, 75 and 90 . At day 15 , platelet count of group B was significantly higher while of group $\mathrm{C}$ was significantly lower than control. At day 60, platelet values of group $\mathrm{B}$ and $\mathrm{C}$ was significantly lower than control (Fig. 2).

\section{Electrolytes}

Sodium: Sodium concentration in group A, B and C was significantly lower than control at day 15,30 and 60. Group B and C had significantly lower values than control at day 45, 75 and 90 (Fig. 4).

Potassium: Potassium ion concentration of all groups was not significantly different from control at day 15 , 30, 45, 60, 75 and 90 (Data not shown).

Chloride ions: Chloride ion concentration of all groups was not significantly different from control at day $15,45,60$ and 90 . These values were significantly lower in group B than control at day 75 (Fig. 4).

Bicarbonate ions: Bicarbonate ions concentration of all groups was not significantly different from control at day 45, 60, 75 and 90 . These values were significantly higher in group B than control at day 15 and 30 (Fig. 4).

\section{Post-mortem examination}

During the study, only one dog from all groups (A, $\mathrm{B}$ and $\mathrm{C}$ ) died (group C). Post-mortem examination in dogs revealed that necrosis and discolouration were absent $(100 \%)$. Intact anastamosis and vascularisation were $100 \%$ and intestines were thick anastamotic $(100 \%)$. There were no bleeding and injuries in the intestinal regions of the dogs.

\section{Discussion}

Jejunectomy was done to evaluate the effects of variable degree of jejunal resection upon clinicobiochemical parameters in dogs. Weight loss occurred in all groups after surgery. With the passage of time, weight gain in all groups occurred in all groups except group $\mathrm{C}$ where $100 \%$ resection was done. These results are in accordance with Yamada et al. [10].

Fecal consistency was watery in all groups postoperatively. This pattern recovered in all groups with the passage of time without any supportive therapy except in group $\mathrm{C}$ where the fecal consistency remained watery till the end of experiment. Similar results have been shown by Wolf et al. [9].

Erythrocytic count of group A, B and C was significantly lower than control. WBCs count varies in different groups at different intervals. This count was 
significantly higher in group A, B and C than control at day 90. Lymphocytic count of different groups was not significantly different from control. Hct values of group A, B and C were significantly lower than control at different intervals. Similar results were reported by Astre et al. [1]. Granulocytic count of group A and C was significantly higher than control at different intervals. $\mathrm{MCH}$ and $\mathrm{MCHC}$ values of group $\mathrm{C}$ was significantly lower than control throughout the study.

Sodium concentration of group A, B and C was significantly lower than control at different intervals while sodium concentration of group $\mathrm{C}$ remained significantly lower than control throughout the experiment. Similar results have been shown by Nightingale [6]. In our study, the jejunectomy had no effect on potassium, chloride and bicarbonate ion concentrations in all groups. These results are in accordance with Loeschke et al. [5] and Vazquez et al. [8].

\section{Conclusions}

Our study showed that $70 \%$ and $80 \%$ jejunectomy had no detrimental effects on the health of dog while $100 \%$ jejunectomy seriously affected body weight, hematological and biochemical parameters.

\section{Acknowledgments}

We are greatly thankful to Ms. Asma Aziz, Research Officer, Biochemistry section VRI, Lahore, Pakistan for her valuable help in biochemical analysis of the samples.

\section{References}

1. Astre C, Gouttebel MC, Saint-Aubert B, Girardot PM, Briand D, Joyeux H. Plasma and jejunal glutamine levels after extensive small bowel resection in dogs. Clin Nutr 1992, 11, 30-34.

2. Bojrab MJ, Slocum B, Ellison GW. Current Techniques in Small Animal Surgery. pp. 248-249, Lippincott William \& Wilkins, Maryland, 1998.

3. Guyton AC, Hall JE. Textbook of Medical Physiology. pp. 813-814. Saunders, Philadelphia, 2005.

4. König HE, Liebich HG. Veterinary Anatomy of Domestic Mammals: Textbook and Colour Atlas. pp. 326. Schattauer, Stuttgart, 2004.

5. Loeschke K, Fabritius H, Welter HF. Adaptation of electrolyte transport in rat large intestine after proximal resection. I. Cecum and colon after $60 \%$ jejunoilectomy. Pflugers Arch 1986, 406, 323-327.

6. Nightingale JM. Management of patients with a short bowel. Nutrition 1999, 15, 633-637.

7. Sharma MC, Pathak NN, Bhat PN. Dogs, Breeding, Nutrition, Diagnosis and Health Management. CBS Publishers \& Distributers, Darya Ganj, 1993.

8. Vázquez CM, Molina MT, Ilundain A. Adaptation of electrolytes and fluid transport in rat small and large intestine after distal small bowel resection. Rev Esp Fisiol 1988, 44, 141-145.

9. Wolf SA, Telander RL, Go VL, Dozois RR. Effect of proximal gastric vagotomy and truncal vagotomy and pyloroplasty on gastric functions and growth in puppies after massive small bowel resection. J Pediatr Surg 1979, 14, 441-445.

10. Yamada S, Mayahara T, Maruyama I, Shibanoki S, Tokuyoshi K, Iso A. Digestant effects of a new digestive enzyme capsule, Excelase, on jejunectomized and pancreato-jejunectomized Beagle dogs (author's transl). Nihon Yakurigaku Zasshi 1978, 74, 49-60.

11. Zar JH. Biostatistical Analysis. 4th ed. pp. 178-189, Prentice Hall, Upper Saddle River, 1999. 